\title{
Building Synergy in Mechanical Engineering Laboratories
}

\author{
A. A. Mobasher, A. R. Jalloh, Z. T. Deng, R. Rojas-Oviedo \\ Mechanical Engineering Department \\ Alabama A\&M University \\ Huntsville, AL 35762 \\ Amobasher@aamu.edu; \\ ajalloh@aamu.edu; aamzxd01@aamu.edu; rojaso@asnaam.aamu.edu
}

\begin{abstract}
Instruction in engineering laboratories provide unique opportunities for students to have hands on experiences and is revealing for them to see that some simple experiments do not provide the "exact" anticipated solution as prescribed by theory. This scenario allows the introduction of practical topics like calibration, error analysis and design of experiments. As valuable as they are, laboratories are an expensive part of the operating budget of any engineering department and in some cases hard decisions are made with regard to frequency of upgrades or in the worst case scenario to drop the laboratory from the plan of study. An alternative is to build up synergistic connectivity among laboratories to distribute the learning as well as distribute the total cost of laboratory equipment.

This paper examines the approach taken by the Mechanical Engineering program at Alabama A\&M University to increase the productivity of each laboratory using common platforms. A central data acquisition system was established. It includes a National Instruments VXI data Acquisition system and Pentium based PC's. Application programs were installed on this central system. Experiment or measurements at each individual laboratories are controlled by the central system and data can be processed through an internal network connecting the ME laboratories. Among the laboratories included in this report are: fluid dynamics, heat and mass transfer, instrumentation of physical systems, propulsion laboratory, manufacturing lab and the automatic controls lab. Laboratory development is integrated to the present curriculum and this may point in the direction of multifunctional laboratories. This approach is being tested and additional laboratories will be brought on line as the needs and support increases in the program.
\end{abstract}




\section{Background}

Alabama A\&M University, (AAMU) was granted the authority to offer two new engineering programs in August 1, 1995. This situation brought to AAMU a unique opportunity to develop two new engineering programs form "a clean sheet of paper" perspective.

From the onset, the objectives of the Mechanical Engineering program at Alabama A\&M university were established. The ME program seeks to provide laboratory experiences to develop students skills in design of experiments, laboratory safety, data acquisition, instrumentation, \& laboratory report writing.

This paper describes the approach taken by the Mechanical Engineering program at Alabama A\&M University in the development of its laboratory structure to enhance productivity and the educational process. Examples of laboratory productivity are discussed in this paper.

\section{Introduction}

Laboratory experiences for undergraduates have always been an integral part of most engineering programs in the United States. While the students gain the opportunity to reinforce their classroom learning, they also get to appreciate the limitations of the theory. The importance of laboratory experimentation dictates the need for the engineer to become familiar with the methods of measurement as well as analysis techniques for interpreting experimental data. Engineering laboratories provide unique opportunities for students to have hands on experiences and is revealing for them to see that some simple experiments do not provide the "exact" anticipated solution as prescribed by theory. This scenario allows the introduction of practical topics like calibration, error analysis and design of experiments.

The authors agree that laboratory experiences prove to be valuable to students and are certainly useful once students become practicing engineers. An essential part of a laboratory exercise is report preparation and presentation. This gives the students the opportunity to enhance their communication skills. The students in the program are required to work in groups in most experiments; therefore, they are able to develop their team/teamwork skillsThese two facets of the education have been ranked as top two in the ranking of best practices for new B.S. graduates by industry [1].

Laboratories are an expensive part of the operating budget of any engineering department and in some cases hard decisions are made with regard to frequency of upgrades or in the worst case scenario to drop the laboratory from the plan of study. An alternative to address the problem of cost of laboratory operation is to build up synergistic connectivity among laboratories to distribute the learning as well as distribute the total cost of laboratory equipment. This approach appears to increase the productivity of each laboratory using common platforms, a central data acquisition system and network connectivity for access to 
data or programs located in different laboratories. Laboratory development is integrated to the present curriculum and this may point in the direction of multifunctional laboratories. Among the laboratories included in this report are: fluid dynamics, heat and mass transfer, instrumentation of physical systems, propulsion laboratory, manufacturing lab and the automatic controls lab.

\section{Inspiring Elements for Laboratory Development and Acquisition}

There are primarily four factors that inspired idea for development of an efficient laboratory system for the mechanical engineering program. First, the newness of the program offered an opportunity to start from a clean sheet of paper. Authors share the view that this is considered an advantage, because before dedicating funds to specific laboratories, the entire laboratory system could be analyzed and be designed for higher productivity. Secondly there are existing private industry and government agency resources available to the university in the northern part of Alabama, in particular, Huntsville, that may reduce the need for ownership of laboratory equipment; i.e. streolitography equipment. Huntsville, Alabama is a town where numerous high tech industries and government agencies coexist. A number of projects from these industries involve projects in manufacturing that may be suitable for joint investigation and training between industry and AAMU. This joint research interest between the AAMU and industry will create a bridge that would close the gap between needs of industry and the educational objectives at AAMU. Third, a well thought system's approach inspired the idea of developing multifunctional laboratories as opposed to standalone laboratories $[2,3,4]$. Finally, existence of the technology, such as internet and intranet and hardware and software that supports this technology, that would make the idea of synergic laboratories realizable. Nowadays, this technology is readily accessible, while such a plan would have been difficult to implement a few years ago.

In the following section we will discuss briefly the Mechanical Engineering curriculum and the laboratory structure that supports this curriculum.

\section{Synergy in Propulsion and Manufacturing Laboratories}

The laboratory development in the ME program at AAMU is not viewed as a self contained or modular package, but as part of a larger integrated system. We consider the complete program in Mechanical Engineering as a system. The curriculum is comprised of two options- a manufacturing option and a propulsion option. Although students graduating from the program with a Bachelor of Science in Mechanical Engineering, each option offers additional competencies for each group in their related area. The approach taken is to form various laboratories that will support both the core laboratories (propulsion and manufacturing), as well as each other. Figure 1. depicts the general setup of the laboratory systems. 
At the core of the system there exists a central data acquisition system that is shared by both options in the program. The curriculum offers courses which include laboratory and are common to both options. These courses are Heat and Mass transfer, Fluid Dynamics, Analysis and Instrumentation of Physical Systems, and Automatic Control System.

Propulsion option offers another course in Analysis and Synthesis of Gas Turbines which is specific to the propulsion option. The ME program has plans for a propulsion laboratory. This laboratory will be eventually equipped with an auxiliary power unit APU, which is used in experiments for a turbojet engine, a hybrid rocket testing stand and a supersonic nozzle testing stand. The laboratory will introduce the students to the fundamentals of: supersonic flow, using supersonic nozzles; propulsion devices, using turbojet engine instrumented and controlled remotely from a control room, hybrid rocket engine performance, combustion phenomena and practices in instrumentation using calibrated pressure sensors, thermocouples, electric and pneumatic valve controllers, calibrated mass flow rate metering devices for gases and liquids, electric pressure transducers, thermocouples and barometers.

The manufacturing option offers an additional course, Design for Manufacture, which also includes a laboratory. To support the manufacturing option, students will be introduced to Flexible Manufacturing Cell (FMC). The FMC will enable the students to learn and identify robots, computer numerical control $(\mathrm{CNC})$ machine, conveyer, parts pallets and templates. It

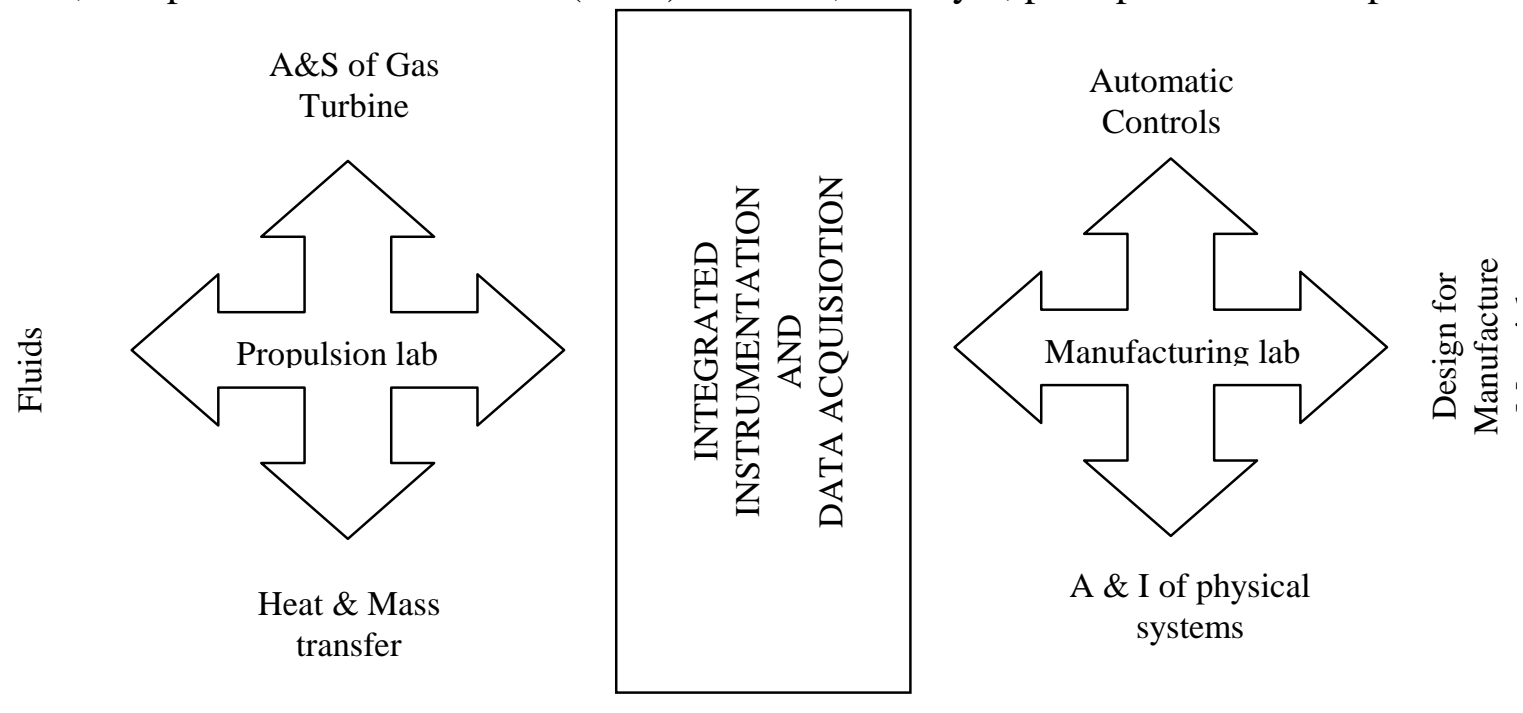

Figure 1. Schematic of the general set up.

also includes the integration of the simulation tools (Computer work station and software) that can be developed to reflect the exact physical layout of the manufacturing related issues to enhance the learning process and to build the students intuitive knowledge as it relates to manufacturing. The laboratory for the manufacturing option is designed to enable the 
students to become familiar with the concepts of production systems, group technology, process control, manufacturing, production planning, materials handling, robotics, flexible manufacturing systems (FMS), rapid prototyping (RP), CAD/CAM, and sensors.

The laboratory will address the need of students working in the areas of capstone courses both in the propulsion and manufacturing options. In addition it will serve the students to work on competition projects sponsored by various organizations such as ASME, AIAA, ASEE, SME. In addition, concepts of stability, control, and instrumentation in Automatic Control Theory may be demonstrated via the robotic manipulators in the manufacturing cell. Automated storage and retrieval system (ASRS) used in the manufacturing laboratory will demonstrate the concepts of Automatic Control.

The multifunctional laboratory may be viewed as those laboratories that may share a particular setup to serve at least two or more courses. Table 1. depicts a list of courses and associated laboratories along with their connectivity structure. The last column in the table lists the potential laboratories that support each course. Some examples of this idea is depicted in the following section:

Example 1. Consider ME 101- Introduction to Mechanical Engineering (item 1) in table 1. This class includes 1 credit hour for the laboratory. In addition the students are required to work as several teams to develop a project in the class (such as design of a glider). As part of their design project students in this class are asked to consider various aspects of the design such as manufacturing options, material selection, cost analysis, and determination of drag and lift on their design. The associated laboratory for this course is ME 360 L-Fluid Dynamics Lab (item 9 in table 1), and access to the ME departments machine shop (item 16). In developing this project the students visit the subsonic wind tunnel in the Fluid Dynamics laboratory and are introduced to the pitot tube and how it is used in measurement of air velocity, drag and lift.

Example 2. consider ME 301 L- Analysis and Instrumentation of Physical Systems, (item 6 ). The supporting laboratories are listed as $(6,7,9,11,14,16)$ or equivalently ME 312L- heat and mass transfer laboratory, ME360L- Fluid Mechanics Lab, ME 432L- Design for Manufacture, and Central Data acquisition system.

As an example, the subsonic wind tunnel used in the fluid dynamics class for the measurement of drag and Lift utilizes a pitot tube. The same set up is used in the Instrumentation of Physical System lab to learn and have hands on experience with the flow measuring devices. In addition, the students in that class can become familiar with the concepts of Data Acquisition, calibration and error analysis. Similarly, thermocouples used in the Heat and Mass Transfer Class to demonstrate Convection and Conduction will be used in the Instrumentation of Physical Systems to do experiments involving, Calibration, Data Acquisition, and Data Analysis. In the ME 432L, the students will be familiarized with the servo motors as well as potentiometers used in the robot arms in that laboratory. 
Table 1. List of courses that include project and/or laboratory and are multifunctional.

\begin{tabular}{|c|l|l|c|c|}
\hline No. & Course & \multicolumn{1}{|c|}{ Title } & $\begin{array}{c}\text { Include } \\
\text { Lab or } \\
\text { Project } \\
\text { (L or P) }\end{array}$ & $\begin{array}{c}\text { Utilizes Lab } \\
\text { No: }\end{array}$ \\
\hline 1 & ME101 & Intro to Mechanical Engineering & L\&P & $1,9,11,16$ \\
\hline 2 & ME205 & Statics & $P$ & 15,16 \\
\hline 3 & ME206 & Dynamics & $P$ & 15,16 \\
\hline 4 & ME210 & Materials Science & $P$ & 15,16 \\
\hline 5 & ME231 & Strength of Materials & $P$ & 15,16 \\
\hline 6 & ME301 & Analysis and Instrumentation of Physical & L\&P & $6,7,9,11,14,15$ \\
\hline 7 & ME312 & Heat and Mass Transfer & L\&P & $7,6,14$ \\
\hline 8 & ME320 & Kinematics and Dynamics of Machinery & P & 15,16 \\
\hline 9 & ME360 & Fluid Mechanics & L\&P & 9,14 \\
\hline 10 & ME412 & Analysis and Synthesis of Gas Turbines and & L\&P & 10,14 \\
\hline 11 & ME432 & Design for Manufacturing and Reliability & L\&P & 11,15 \\
\hline 12 & ME451 & Automatic Control Systems & L\&P & $12,6,11,14$ \\
\hline 13 & ME470 & Mechanical Engineering Design & & access to all \\
\hline 14 & N/A & Central Data Acquisition System & N/A & - \\
\hline 15 & N/A & Manufacturing Laboratory & N/A & - \\
\hline 16 & N/A & Machine Shop & N/A & - \\
\hline
\end{tabular}

Example 3. Consider ME 451- Automatic Control Theory. This class consists of a set of laboratory experiments as well as a project. The laboratories that support this course are listed as the core experiments designed explicitly for this class. The supporting laboratories include laboratories for ME 301L-Analysis and Instrumentation of Physical System Lab (item 6), ME 432 L-Design for manufacture Lab (item 11) and the central Data acquisition system (item 14 in table 1 ).

In this laboratory, the students have access to various sensors and actuators that are available in ME 301 lab for study, such as thermocouples, pressure transducers, flow-meters, and DC motors to name a few. These equipment may be used by students in the development of their project or a particular laboratory experiment as needed. For ME432 L the students will be able to benefit from the automation process used in the Flexible Manufacturing Cell. In this laboratory the students gain additional insight in the operation of servomotors and potentiometers used in the robot arms. Also they gain hands on experience on programming and control of the robotics in that laboratory. The National Instruments Central Data Acquisition system (VXI) is used to perform a set of basic core laboratory experiments such as controlling and maintaining the level of a tank filled with water and selection of appropriate control parameters for this experiment. 
It must be noted not all the courses listed require laboratory practice; however, the students in mechanical engineering program are required to develop a project in every class. Some of the laboratory modules is intended to assist students in development process of their project. For example all courses marked with "P" include a project which can utilize the laboratories indicated in their corresponding row.

\section{Discussions and Conclusions}

The Mechanical Engineering Department at Alabama A\&M University has utilized a systems approach to the development of it's laboratory. The newness of this program has offered a chance to develop a laboratory system from a clean sheet of paper- rather than upgrading the current systems or assimilating stand alone laboratories. The laboratory system under development is designed to be multifunctional and synergistic. These two features of the laboratory allows the department to maximize it's resources while giving the students the necessary laboratory experience as described in it's program objectives. The idea of synergistic laboratory lead to minimization of redundancies. Also by synergistic laboratory development, the chances of elimination of a laboratory from the program due to limited budget may be reduced and the upgrades are obtained easier since the funds are allocated to a fewer laboratory equipment that serve the same number of courses. Another aspect of multifunctional and synergistic laboratories is that they require less space since some of the redundancies are eliminated. One drawback of this approach is that the scheduling of the courses and laboratories to minimize conflict and meet the objectives becomes challenging. Although elimination of equipment redundancies saves departmental resources, a breakdown or a loss of an equipment that is considered multifunctional may affect all of the labs that are associated with it. Based on these factors, the authors recommend that some level of redundancy be built into this system.

This idea which is currently being tested in a few courses in the Mechanical Engineering department appears to be effective in delivering the educational objectives of the department. Based on the survey of the first generation of the graduates (although few) from the program, it appears that the training they received from the program has enabled them to perform very well in their mechanical engineering manufacturing design positions. These preliminary results gives the author confidence on the approach taken in the evolution of the laboratory system.

\section{Bibliography/References}

1. Manufacturing Education Plan: Phase I Report. "Industry Identifies Competency Gaps Among Newly Hired Engineering graduates. Published by the Society of Manufacturing engineers and the SME Education Foundation, 1997

2. R. Rojas-Oviedo, Z. T. Deng, A. Mobasher, A. Jalloh, "Implementation of a Systems Approach for Curriculum Design", ASEE Conference, St. Louis MO, June 2000,

3. R. Rojas-Oviedo, Z. T. Deng, A. Mobasher, A. Jalloh, "Development of Engineering Competencies in 
Freshman Courses", ASEE Conference, St. Louis MO, June 2000

4. R. Rojas-Oviedo, Z. T. Deng, A. Mobasher, A. Jalloh, "Synthesis of Engineering Best Practices and ABET AC2K into a New Mechanical Engineering Curriculum”, ASEE Conference, St. Louis MO, June 2000.

AMIR MOBASHER

Amir Mobasher is Assistant Professor of the Department of Mechanical Engineering at Alabama A\&M University in Huntsville, AL. He holds a Ph.D. degree in Mechanical Engineering from University of Alabama in Huntsville. He has research interest in the areas of Computational Fluid Dynamics, Biomechanics, and Control and Automation. His primary area of interest at AAMU is Automation, Control and Fluid Dynamics. After graduating from UAH, he worked at U.S. Army Aeromedical Research Laboratory at Fort Rucker, Alabama. During his employment there, his research focused on aircrew protection and head-supported mass and center of mass placement for the U.S. Army aviation. As a Ph.D. candidate at $\mathrm{UAH}$, his research focused primarily on shock-wave turbulent boundary layer interactions

\section{ABDUL JALLOH}

A. Jalloh is Assistant Professor of the Department of Mechanical Engineering at Alabama A\&M University in Huntsville, AL. Dr. Jalloh earned his Ph.D.in Mechanical Engineering, with a minor in Engineering Mechanics from the University of Arizona, he obtained his M.S. Mechanical Engineering also from the University of Arizona, and he holds a B.Eng. in Mechanical Engineering from University of Sierra Leone.

His research interest is in areas of mechanical vibrations, structural dynamics, structural mechanics, applied elasticity, probabilistic design, finite element analysis, manufacturing and reliability.

\section{ZENGTHAO DENG}

Z.T. Deng is Assistant Professor of the Department of Mechanical Engineering at Alabama A\&M University in Huntsville, AL. Dr. Deng has an extensive background and research experience in numerical simulation in particular high speed aerodynamics/flows with heat transfer phenomena. He earned his Ph.D., Aerospace Engineering, University of Tennessee, 1991., and his Bachelor of Science, Aerospace and Mechanical Engineering, from Beijing University of Aeronautics and Astronautics in 1985.

\section{RUBEN ROJAS-OVIEDO}

Ruben Rojas-Oviedo is Chairperson and Associate Professor of the Department of Mechanical Engineering at Alabama A\&M University in Huntsville AL. Dr. Rojas-Oviedo has international engineering experience working both in academe and industry. He has an engineering consulting company and conducts applied research. He earned a $\mathrm{Ph}$. D. In Aerospace Engineering from Auburn University, he has two Masters degrees one in Mechanical Engineering from N.C. State at Raleigh and the other in Applied Mathematics from Auburn. He earned a B.S. degree in Aeronautical Engineering from the National Polytechnic Institute - Escuela Superior de Ingenieria Mecanica y Electrica - in Mexico City, Mexico 